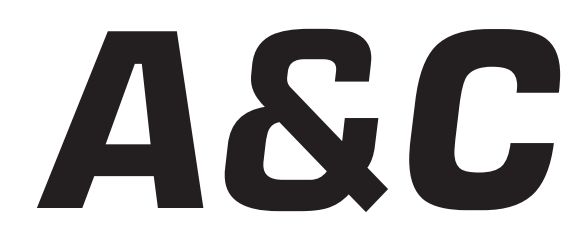

Revista de Direito Administrativo \& Constitucional

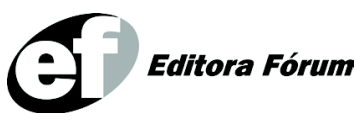

A\&C R. de Dir. Administrativo e Constitucional, Belo Horizonte, ano 6, n. 24, p. 1-246, abr.jun. 2006 


\section{A\&C REVISTA DE DIREITO ADMINISTRATIVO E CONSTITUCIONAL}

\section{IPDA}

Instituto Paranaense

de Direito Administrativo

Direção Geral

Romeu Felipe Bacellar Filho

Direção Editorial

Paulo Roberto Ferreira Motta

Direção Executiva

Emerson Gabardo

Conselho de Redação

Edgar Chiuratto Guimarães

Adriana da Costa Ricardo Schier

Célio Heitor Guimarães

Conselho Editorial

Adilson Abreu Dallari

Alice Gonzáles Borges

Carlos Ari Sundfeld

Carlos Ayres Britto

Carlos Delpiazzo

Cármen Lúcia Antunes Rocha

Celso Antônio Bandeira de Mello

Clèmerson Merlin Clève

Clóvis Beznos

Enrique Silva Cimma

Eros Roberto Grau

Fabrício Motta

Guilhermo Andrés Muñoz (in memoriam)

Jaime Rodríguez-Arana Muñoz

Jorge Luís Salomoni
José Carlos Abraão

José Eduardo Martins Cardoso

José Luís Said

José Mario Serrate Paz

Juan Pablo Cajarville Peruffo

Juarez Freitas

Julio Rodolfo Comadira

Luís Enrique Chase Plate

Lúcia Valle Figueiredo

Manoel de Oliveira Franco Sobrinho

(in memoriam)

Marçal Justen Filho

Marcelo Figueiredo

Márcio Cammarosano

Maria Cristina Cesar de Oliveira
Nelson Figueiredo

Odilon Borges Junior

Pascual Caiella

Paulo Eduardo Garrido Modesto

Paulo Henrique Blasi

Paulo Neves de Carvalho (in memoriam)

Paulo Ricardo Schier

Pedro Paulo de Almeida Dutra

Regina Maria Macedo Nery Ferrari

Rogério Gesta Leal

Rolando Pantoja Bauzá

Sérgio Ferraz

Valmir Pontes Filho

Yara Stropa

Weida Zancaner

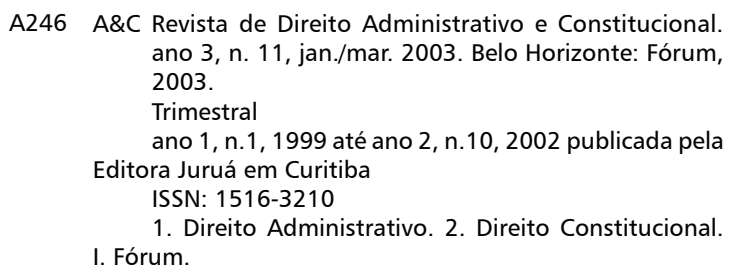

A246 A\&C Revista de Direito Administrativo e Constitucional. ano 3, n. 11, jan./mar. 2003. Belo Horizonte: Fórum, 2003.

Trimestral

ano 1, n.1, 1999 até ano 2, n.10, 2002 publicada pela Editora Juruá em Curitiba

ISSN: 1516-3210

1. Direito Administrativo. 2. Direito Constitucional. I. Fórum.

CDD: 342 CDU: 33.342

(c) Editora Fórum Ltda. 2006

Todos os direitos reservados. É proibida a reprodução total ou parcial, de qualquer forma ou por qualquer meio eletrônico ou mecânico, inclusive através de processos xerográficos, de fotocópias ou de gravação, sem permissão por escrito do possuidor dos direitos de cópias (Lei nº 9.610, de 19.02.1998).

\section{Editora Fórum Ltda}

Av. Afonso Pena, 2770 - 15\%16ªndar - Funcionários

CEP 30130-007 - Belo Horizonte/MG - Brasil

Tel.: 08007043737

Internet: www.editoraforum.com.br

e-mail: editoraforum@editoraforum.com.br
Editor responsável: Luís Cláudio Rodrigues Ferreira Projeto gráfico e diagramação: Luis Alberto Pimenta Revisora: Olga M. A. Sousa

Pesquisa jurídica: Fátima Ribeiro - OAB/MG 74868

Bibliotecária: Alessandra Rodrigues da Silva CRB 2778/MG 6a Região

Os conceitos e opiniões expressas nos trabalhos assinados são de responsabilidade exclusiva de seus autores.

Impressa no Brasil / Printed in Brazil

Distribuída em todo Território Nacional 


\title{
Considerações sobre a ação direta interventiva e a proteção dos direitos fundamentais
}

\author{
Heloísa da Silva Krol \\ Mestranda em Direito do Estado/UFPR
}

Palavras-chave: Ação direta interventiva. Direitos fundamentais. Intervenção da União nos Estados-membros e no Distrito Federal. Vínculo federativo. Intervenção federal. Direitos humanos.

Neste artigo busca-se tratar de alguns pontos relacionados à ação direta interventiva, porém dentro do contexto de proteção dos direitos fundamentais. Desta forma, não serão abordadas especificamente questões referentes ao processo de intervenção, suas hipóteses e pressupostos.

Contudo, necessárias se fazem algumas considerações a respeito da natureza jurídica da ação direta interventiva, estabelecendo assim algumas premissas.

Para possibilitar a análise mais detalhada da proteção dos direitos fundamentais, prefere-se enfocar apenas a ação direta interventiva que viabiliza a intervenção da União nos Estados-membros e no Distrito Federal. Não se desconhece, no entanto, a possibilidade de intervenção dos Estados-membros nos Municípios para assegurar a observância dos princípios indicados na Constituição Estadual, conforme disposto no artigo 35, inciso IV da Constituição Federal. ${ }^{1}$

Desta forma, como medida extrema para manutenção do pacto federativo, a Constituição Federal de 1988 alude à intervenção da União nos Estados-membros, Distrito Federal e Municípios localizados em Território Federal (artigos 34 e 35).

Trata-se de mecanismo excepcional, porém necessário para que se assegure a indissolubilidade do vínculo federativo. ${ }^{2}$

As hipóteses de intervenção federal são taxativas e vêm previstas

\footnotetext{
A delimitação é necessária para fins de conferir maior enfoque à tutela dos direitos fundamentais em sede de ação direta interventiva, tendo em conta que o princípio constitucional da proteção aos direitos humanos não foi necessariamente previsto em todas as Constituições Estaduais como hipótese específica ensejadora da intervenção nos Municípios. A título de exemplo, a Constituição do Estado do Paraná não enumerou quais os princípios cujo descumprimento autoriza o manejo da ação direta interventiva (artigo 20, IV da Constituição do Estado do Paraná), razão pela qual todos os princípios constitucionais estaduais passam a assumir a característica de sensíveis (CLĖVE, 2000, p. 390).

2 Conforme TEMER, a intervenção federal é da essência do sistema federativo, pois visa à mantença da integridade dos princípios basilares da Constituição. De um lado, objetiva a proteção do território e da divisão territorial (artigo 34, I e II da Constituição Federal), de outro, pretende a paz social, a moralidade
}

A \& C R. de Dir. Administrativo e Constitucional, Belo Horizonte, ano 6, n. 24, p. 87-96, abr.jun. 2006 
nos incisos do artigo 34 da Constituição Federal. ${ }^{3}$ Neste rol, estabeleceu-se a possibilidade de intervenção da União nos Estados-membros e Distrito Federal para assegurar a observância dos princípios constitucionais sensíveis, elencados nas alíneas do inciso VII do artigo 34 da Constituição Federal, hipótese esta que autoriza o manejo do objeto em exame: a ação direta interventiva.

Com efeito, a decretação de intervenção federal fundada no inciso VII do artigo 34 da Constituição Federal depende de representação do Procurador-Geral da República e de provimento desta pelo Supremo Tribunal Federal, conforme disposição do artigo 36, inciso III da Constituição Federal.

Apesar da Constituição aludir a "representação", a doutrina é uníssona no sentido de que se trata de verdadeira ação, cuja competência o Supremo Tribunal Federal detêm de forma concentrada. ${ }^{4}$

A ação direta interventiva se insere dentro dos mecanismos de controle direto de constitucionalidade, ao lado das ações diretas de inconstitucionalidade por ação e por omissão, da ação declaratória de constitucionalidade e da argüição de descumprimento de preceito fundamental.

Guarda, de outro lado, muitas especificidades em relação a estas ações. Com efeito, a Constituição brasileira de 1891 consolidou o controle difuso de constitucionalidade, inspirando-se no modelo norte-americano, ${ }^{5}$ o qual possibilita que todos os juízes e tribunais façam a análise da constitucionalidade dos atos do poder público incidentalmente durante o trâmite de qualquer processo de sua competência. ${ }^{6}$ A questão constitucional não é o objeto precípuo da demanda, mas sim uma prejudicial que deve ser enfrentada antes do julgamento do mérito.

administrativa e o adequado cuidado com as finanças do Estado (artigo 34, III e V, "a" da Constituição Federal). Visa ainda garantir a tripartição dos poderes (artigo 34, IV da Constituição Federal) e a observância da forma republicana, do sistema representativo e do regime democrático, dos direitos da pessoa humana, da autonomia municipal e da prestação de contas da Administração Pública direta e indireta (artigo 34, VII da Constituição Federal) (TEMER, 1992, p. 71).

3 SILVA, 1993, p. 424.

4 CLĖVE, 2000, p. 128. Nesta senda, Alfredo Buzaid asseverou que o poder de submeter ao julgamento do Supremo Tribunal Federal o ato argüido de inconstitucionalidade representa o exercício de direito de ação, pois o Supremo não responde a uma consulta, mas sim decide uma questão concreta (BUZAID, 1958, p. 101-107). No mesmo sentido: FERREIRA, n. 164, p. 09, abr./jun. 1986.

5 A competência do Judiciário é difusa, podendo ser exercitada no curso das demandas, por qualquer juiz ou tribunal, desenvolvendo-se, assim, o judicial review, que foi definitivamente incorporado ao direito constitucional americano em $1803 \mathrm{com}$ a decisão do Chief Justice Marshall no caso Marbury v. Madison (CAPPELLETTI, 1999, p. 103).

6 Rigorosamente, conforme lembra Gilmar Ferreira Mendes, o Decreto n. 848/1890 já havia consolidado o controle difuso de constitucionalidade no direito brasileiro (MENDES, ano 06, n. 23, p. 32, abr./jun. 1998a). 
O modelo difuso consolidou-se no direito pátrio e subsiste até a atualidade. $^{7}$

Entretanto, com a Constituição de 1934, outro modelo de controle de constitucionalidade ganhou atenção do constituinte através da previsão da ação direta interventiva: o concentrado, inspirado no direito austríaco. ${ }^{8}$

Nesta Carta, previu-se que a competência para a apreciação da lei que decretava a intervenção federal concentrava-se no Supremo Tribunal Federal. ${ }^{9}$ A Constituição de 1946 deu a ação direta interventiva o perfil que conserva até hoje. ${ }^{10}$ Desta forma, consolidou-se também no direito pátrio o controle concentrado de constitucionalidade.

Contudo, o controle de constitucionalidade que a ação direta interventiva desencadeia, apesar de concentrado em um único órgão, não é abstrato, nos termos propugnado pelo modelo austríaco.

A análise tem em vista um caso concreto frente ao qual se afere a violação dos princípios constitucionais sensíveis, ${ }^{11}$ razão pela qual podese dizer que rigorosamente somente com a Emenda n. 16/65 é que foi estabelecido o controle abstrato de constitucionalidade no Brasil.

Diante disto, não é possível inserir a ação direta interventiva nem como instrumento de controle concreto/difuso, nem abstrato/concentrado, dentro da tradicional dicotomia apontada correntemente na doutrina pátria, ${ }^{12}$ tratando-se de mecanismo de fiscalização concreta e concentrada da constitucionalidade.

A parametricidade na ação direta interventiva também é específica, pois viabiliza a análise da compatibilidade de comportamentos estatais

\footnotetext{
7 Contudo, Sergio Fernando Moro ressalva que a Constituição de 1988 dispôs apenas indiretamente acerca do controle difuso e incidental, sendo este fundamentado no princípio da inafastabilidade da jurisdição, insculpido no artigo $5^{\circ}$, inciso XXV da Carta e nas hipóteses de cabimento do recurso extraordinário, previstas no artigo 102, inciso III, também da Constituição Federal (MORO, 2001, p. 130).

8 A Constituição austríaca de 1920 instituiu uma Corte Constitucional com competência para, de modo concentrado e por via de ação direta, fiscalizar a constitucionalidade, independentemente de caso concreto (CAPPELLETTI, 1999, p. 104).

${ }^{9}$ Conforme ressalva Luis Roberto Barroso, sob a égide da Constituição de 1934 competia ao Congresso Nacional, mediante lei, decretar a intervenção federal por descumprimento de princípio constitucional sensível, prestando-se a ação direta interventiva à aferição da constitucionalidade da lei que decretava a intervenção, não do ato motivador (BARROSO, 2004, p. 251).

${ }^{10}$ Observe-se apenas que até a Constituição de 1967, a execução da medida, quando decorrente de ação interventiva, era de competência do Congresso Nacional, não do Presidente da República. Contudo, a partir da Constituição de 1946 o juízo da constitucionalidade do ato motivador da decretação de intervenção foi conferido ao Supremo Tribunal Federal (BARROSO, 2004, p. 251).

${ }_{11}$ CLÈVE, 2000, p. 125

12 Via de regra, esta questão não é percebida, apontando, a doutrina, que o controle de constitucionalidade concreto corresponde ao difuso. Neste sentido: SILVA, 1993, p. 51. De outra banda, fazem esta ressalva: CLEVE, 2000, p. 125; BARROSO, 2004, p. 49.
} 
apenas em face dos princípios constitucionais sensíveis elencados no artigo 34, VII da Constituição Federal, não de toda esta, ${ }^{13}$ como ocorre em sede de ação direta de inconstitucionalidade por ação e por omissão. ${ }^{14}$

Abarca a análise de atos normativos e administrativos (materiais), ${ }^{15}$ bem como de omissões estatais, pois em que pese o artigo $36, \S 3^{\circ}$ da Constituição Federal aludir a "ato impugnado", o artigo 34, inciso VII prescreve apenas que a União não intervirá exceto para "assegurar a observância" dos princípios constitucionais sensíveis. Diante disso, entendese possível a propositura de ação interventiva na hipótese de omissão normativa. ${ }^{16}$

As omissões de atos estaduais concretos que violem princípios constitucionais sensíveis também são impugnáveis. ${ }^{17}$ Este, aliás, foi o entendimento do Supremo Tribunal Federal no julgamento da ação direta interventiva $\mathrm{n}^{\mathrm{o}} 114-\mathrm{MT} .^{18}$ Trata-se, aliás, de leading case.

Outra especificidade da ação direta interventiva que tem importância quando se fala em concretização dos direitos fundamentais é a modalidade de declaração de inconstitucionalidade veiculada e o papel desempenhado pelo Supremo Tribunal Federal.

Em sede de ação direta interventiva, a declaração de inconstitucionalidade proferida pelo Supremo Tribunal Federal não nulifica o ato, nem autoriza o argüente a subtrair-se de sua esfera de incidência. ${ }^{19}$

Conforme Gilmar Ferreira Mendes, trata-se de declaração de inconstitucionalidade sem pronúncia de nulidade, pois o Supremo limita-se, no

\footnotetext{
${ }^{13}$ Vale ressaltar que mesmo em sede de ação direta genérica não é possível argüir a inconstitucionalidade de normas constitucionais elaboradas pelo poder constituinte originário. Não se pode, neste sentido, falar em inconstitucionalidade de normas constitucionais como no direito alemão (BACHOF, 1994, p. 48-71).

${ }^{14} \mathrm{~A}$ argüição de descumprimento de preceito fundamental também tem parâmetro específico, pois a fiscalização da constitucionalidade é feita frente aos preceitos fundamentais decorrentes da Constituição Federal. Não há entendimento consolidado acerca da caracterização dos preceitos fundamentais, havendo um certo consenso doutrinário em identificar como tais os princípios fundamentais do Título I da Constituição Federal, os direitos e garantias fundamentais, os princípios constitucionais sensíveis e as cláusulas pétreas (CUNHA JUNIOR, 2004, p. 571).

$15 \mathrm{O}$ entendimento de que só os atos normativos estariam sujeitos à ação direta interventiva (BRASIL. Supremo Tribunal Federal. Representação n. 94. Relator: Ministro Castro Nunes, 1948) foi revisto pelo Supremo Tribunal (Recurso em Mandado de Segurança n. 14.691. Relator: Victor Nunes Leal. DJU 16.06.1965). Neste sentido, BUZAID já havia se manifestado, asseverando que qualquer ato, oriundo de qualquer dos poderes do Estado, conquanto que ofenda os princípios sensíveis, constitui objeto da ação direta interventiva (BUZAID, 1958, p. 102). No mesmo sentido: MIRANDA, 1970, p. 258.

${ }^{16}$ CLĖVE, 2000, p. 136.

17 TAVARES, 1998, p. 144

${ }^{18}$ Cuida-se de ação interventiva conhecida, mas julgada improcedente em razão das providências tomadas pelas autoridades para restabelecer a normalidade. No caso, o Procurador Geral da República representou ao Supremo Tribunal Federal para o fim de, mediante intervenção federal no Estado-membro, assegurar a observância do princípio do respeito aos direitos da pessoa humana, pois presos foram linchados e queimados vivos pela população do município de Matupá-MT, omitindo-se, na ocasião, a autoridade policial (Intervenção Federal n. 114/MT. Relator: Ministro Nery da Silveira, DJ 27.09.96).

${ }^{19}$ CLÈVE, 2000, p. 130.
}

A \& C R. de Dir. Administrativo e Constitucional, Belo Horizonte, ano 6, n. 24, p. 87-96, abr./jun. 2006 
processo preliminar de intervenção federal, a constatar eventual ofensa aos princípios sensíveis, ocorrendo a suspensão do ato impugnado somente mediante providência do Presidente da República. ${ }^{20}$

Entretanto, com a procedência do pedido, o Presidente da República deverá (ato vinculado) decretar intervenção federal no Estado ou no Distrito Federal para restabelecer a normalidade. ${ }^{21}$ No decreto deverão ser especificados a amplitude, o prazo e as condições de execução (artigo $36, \S 1^{\circ}$ da Constituição Federal), oportunidade em que serão estabelecidas as condições para voltar a normalidade. ${ }^{22}$

Assentados estes pontos, passa-se ao enfoque da inovação trazida pela Constituição de 1988: a consolidação da proteção dos direitos humanos como princípio constitucional sensível e ensejador da propositura da ação direta interventiva.

Subsiste, desta forma, um amplo espaço de operatividade prática para a ação direta interventiva, tendo em vista que viabiliza a tutela dos direitos da pessoa humana em face de atos e omissões tanto normativos quanto materiais dos Estados-membros e do Distrito Federal.

A ressalva é pertinente diante da posição levantada por alguns doutrinadores de que com a previsão da ação direta de inconstitucionalidade pela Emenda 16/65, a ação direta interventiva passou a ocupar papel pouco importante, pois os atos estatais normativos passaram a ser passíveis de fiscalização por via de ação direta de inconstitucionalidade, que tem como conseqüência a retirada do ato impugnado do ordenamento. ${ }^{23}$

Esta orientação doutrinária não se atenta para o fato de que a ação direta interventiva não foi totalmente absorvida pela ação direta de inconstitucionalidade, a qual se presta apenas à impugnação de atos normativos, enquanto a ação direta interventiva possibilita também a impugnação de atos e omissões concretos. ${ }^{24}$

Trata-se, portanto, de importante instrumento para a concretização dos direitos humanos em face de ações e omissões inconstitucionais.

\footnotetext{
${ }^{20}$ MENDES, 1998b, p. 285.

${ }^{21}$ Tratando-se de ato, antes da decretação da intervenção deverá este ser suspenso (art. 36, $\S 3^{\circ}$ da Constituição Federal). Só em caso de insuficiência desta medida, deverá ser decretada a intervenção. A situação é diferente quando se tratar de omissão, pois a normalidade deverá ser restabelecida de outra forma. A intervenção também não cabe quando o Estado ou o Distrito Federal providenciar a satisfação do princípio sensível violado pela revogação do ato viciado ou pelo suprimento da omissão violadora (CLĖVE, 2000, p. 137).

22 MENDES, 1998b, p. 285

23 BARROSO, 2004, p. 252

${ }^{24}$ Clèmerson Merlin Clève ressalva expressamente esta peculiaridade (2000, p. 138).
} 
Com efeito, apesar de haver uma certa confusão entre as expressões direitos humanos e direitos fundamentais, sendo usadas constantemente como sinônimos, necessário se faz tecer algumas distinções.

Os direitos humanos são aqueles reconhecidos ao ser humano como tal, independentemente de sua vinculação com determinada ordem constitucional, razão pela qual aspiram à validade universal, revelando um caráter supranacional. ${ }^{25}$ Já os direitos fundamentais são aqueles direitos positivados na esfera do direito constitucional de determinado Estado. ${ }^{26}$

Desta maneira, conforme Antônio Perez Luño, o conceito de direitos humanos tem contornos mais amplos do que o de direitos fundamentais, que constituem o conjunto de direitos e liberdades institucionalmente reconhecidos e garantidos por determinado Estado. ${ }^{27}$

Apesar destas considerações, há que se reconhecer a íntima relação entre direitos humanos (tutelados através da ação direta interventiva) e direitos fundamentais, pois a maior parte das Constituições do pós-guerra se inspiraram na Declaração Universal de 1948 e demais documentos internacionais, ocorrendo, assim, um processo de aproximação. ${ }^{28}$

Em que pese esta ressalva, pretende-se enfocar neste breve ensaio apenas os direitos fundamentais, abarcados no conceito de direitos humanos, conferindo ênfase aos valores positivados na Constituição de 1988.

Esta restrição se justifica para enfatizar uma das principais nuances da ação direta interventiva: a possibilidade de servir como instrumento para a concretização dos direitos fundamentais em face de omissões estatais inconstitucionais dentro do contexto do processo interventivo.

A doutrina é uníssona no sentido de que o mero não fazer não caracteriza uma omissão inconstitucional. ${ }^{29}$ É necessário aferi-la em face de uma imposição constitucional certa e determinada, razão pela qual esta abordagem é restrita aos direitos fundamentais, pois a concretização destes foi inquestionavelmente imposta em norma constitucional.

A omissão dos Estados-membros no que toca a implementação dos direitos fundamentais viola um princípio constitucional sensível,

\footnotetext{
${ }^{25}$ MIRANDA, J., 1983, p. 51. Ingo Wolfgang Sarlet distingue ainda os direitos humanos dos direitos dos homens, apontando que os primeiros são positivados na esfera internacional, ao passo que os segundos são aqueles naturais, não positivados (A Eficácia dos Direitos Fundamentais. 2. ed. Porto Alegre: Livraria do Advogado, 2001. p. 34).

${ }^{26}$ SARLET, Ingo Wolfgang. A Eficácia dos Direitos Fundamentais. 2. ed. Porto Alegre: Livraria do Advogado, 2001. p. 33.

${ }^{27}$ LUÑO, 1995, p. 46.

${ }^{28}$ SARLET, Ingo Wolfgang. A Eficácia dos Direitos Fundamentais. 2. ed. Porto Alegre: Livraria do Advogado, 2001. p. 35

${ }^{29}$ CANOTILHO, 2001, p. 481.
}

A \& C R. de Dir. Administrativo e Constitucional, Belo Horizonte, ano 6, n. 24, p. 87-96, abr./jun. 2006 
autorizando a decretação da intervenção federal através da ação direta interventiva.

Aliás, o que respaldou a já mencionada ação interventiva $n^{\circ} 114-$ MT foi a omissão das autoridades policiais em fazer respeitados os direitos humanos, tendo o Procurador-Geral da República proposto a medida para o fim de efetivar proteção ao direito fundamental à vida e à integridade física dos custodiados. ${ }^{30}$

Desta forma, a violação a qualquer direito fundamental por parte dos Estados-membros dá ensejo à propositura da ação direta interventiva. Note-se, não apenas os direitos de defesa, mas também os direitos prestacionais abrem esta hipótese.

Neste ponto, é pertinente retomar a distinção estabelecida por Robert Alexy entre direitos a ações negativas e direitos a ações positivas. Os direitos a ações negativas abarcam os direitos a que o Estado não impeça determinadas ações, não afete determinadas propriedades ou situações e não elimine determinadas posições jurídicas do titular do direito. Os direitos às ações positivas se dividem em direitos a prestações fáticas e direitos a

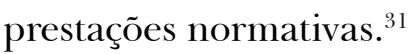

Os direitos às prestações normativas são direitos à imposição de normas. Dependem de uma atuação do Legislativo. Caso a omissão do órgão legislativo estadual afete direitos fundamentais indispensáveis para assegurar a existência digna, esta situação amolda-se a uma hipótese de cabimento da ação interventiva. ${ }^{32}$

Os direitos à prestações fáticas são identificados com os direitos sociais. ${ }^{33}$ Exigem o comportamento ativo por parte do Estado e sua inércia gera também uma omissão inconstitucional (omissão de atos materiais), sindicável em sede de ação direta interventiva, tendo em vista que para

\footnotetext{
30 VELLOSO, n. 187, jan./mar. 1992, p. 31.

31 ALEXY, 1997, p. 189.

32 SILVA, 1993, p. 425.

${ }^{33}$ Tem-se, entretanto, que mesmo os direitos sociais podem compreender posições jurídicas subjetivas não coincidentes com os direitos a prestações, como direito de greve (MORO, 2001, p. 108). No mesmo sentido, Luis Roberto Barroso assevera que as normas que os consagram investem os jurisdicionados em posições jurídicas de três grupos: as que geram situações prontamente desfrutáveis, dependentes apenas de uma abstenção, como o direito de greve; as que ensejam a exigibilidade de prestações positivas do Estado, como à proteção da saúde e previdência social, observando que a ausência de prestação será sempre inconstitucional e sancionável e posições jurídicas que contemplam interesses cuja realização depende da edição de norma infraconstitucional integradora, ressalvando que a Constituição não delega ao legislador competência para conceder os direitos, concedendo ela própria. Portanto, ao legislador incumbe tão somente instrumentalizar sua realização e faltando com este dever dá ensejo a inconstitucionalidade por omissão (BARROSO, 2002, p. 108-112).
} 
fins de controle concreto de constitucionalidade o conceito de atos e omissões inconstitucionais é mais abrangente, não se restringindo aos atos e omissões de cunho normativo. ${ }^{34}$

Ademais, verifica-se que dentro do conjunto de direitos prestacionais há um núcleo essencial que a doutrina denominou mínimo existencial. Esta construção doutrinária se respalda no princípio da dignidade da pessoa humana e no direito à vida, à integridade física e a liberdade. ${ }^{35}$ Assim, atribui-se ao indivíduo o direito subjetivo de exigir do Estado prestações que garantam uma existência digna. ${ }^{36}$

Ana Paula de Barcellos defende que neste núcleo encontra-se o conjunto de prestações materiais essenciais sem as quais o indivíduo se encontrará abaixo da linha da dignidade. Conclui, a autora, que o mínimo existencial é composto de quatro elementos: educação fundamental, saúde básica, assistência aos desamparados e acesso à Justiça (elemento instrumental). ${ }^{37}$

Aliás, observa a autora que há um consenso de que uma pessoa não tem a sua dignidade respeitada "se não tiver o que comer ou o que vestir, se não tiver oportunidade de ser alfabetizada, se não dispuser de alguma forma de abrigo". ${ }^{38}$

No mesmo sentido, Andreas Krell aponta que o mínimo existencial incluirá sempre um atendimento básico e eficiente de saúde, o acesso à alimentação e vestimentas, à educação fundamental e à moradia. ${ }^{39}$

Assim, uma vez reconhecida a omissão estatal no que toca à implementação dos direitos prestacionais, notadamente daqueles considerados mínimos, como o direito à educação fundamental, a intervenção federal se torna medida cabível.

A proteção dos direitos sociais mínimos foi inclusive reforçada por outro princípio constitucional sensível: o da aplicação do mínimo exigido da receita resultante de impostos estaduais, compreendida a proveniente de transferências, na manutenção e desenvolvimento do ensino e serviços públicos de saúde (artigo 34, VII, "e" da Constituição Federal).

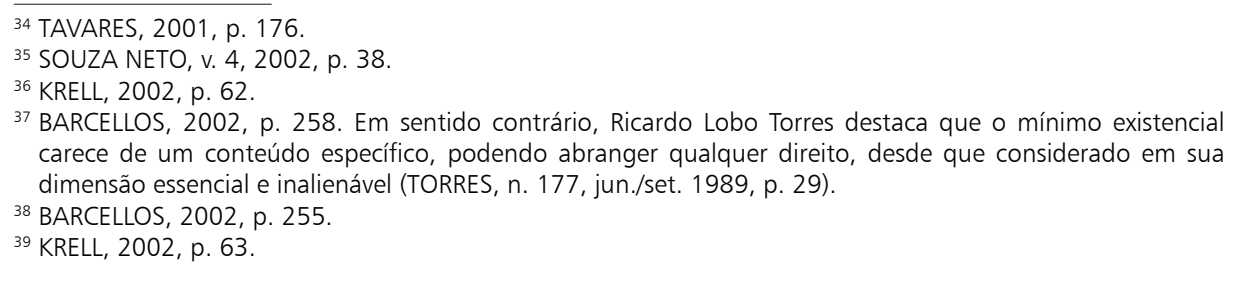

A \& C R. de Dir. Administrativo e Constitucional, Belo Horizonte, ano 6, n. 24, p. 87-96, abr./jun. 2006 
Esta disposição foi inserida pela Emenda Constitucional no ${ }^{\circ}$ 14/1996 e só vem a reforçar a proteção dos direitos fundamentais, principalmente dos denominados mínimos, em face das omissões inconstitucionais dos Estados-membros.

Desta forma, a ação direta interventiva teve a sua operatividade prática renovada com a Constituição de $1988,{ }^{40}$ tratando-se de importante instrumento para a proteção dos direitos fundamentais.

\section{Referências}

ALEXY, R. Teoria de los Derechos Fundamentales. Madrid: Centro de estudios constitucionales, 1997.

BACHOF, O. Normas Constitucionais Inconstitucionais? Tradução de José Manuel M. Cardoso da Costa. Coimbra: Almedina, 1994.

BARCEllos, A. P. de. A Eficácia Jurídica dos Princípios Constitucionais: o Princípio da Dignidade da Pessoa Humana. Rio de Janeiro: Renovar, 2002.

BARROSO, L. R. O Controle de Constitucionalidade no Direito Brasileiro: Exposição Sistemática da Doutrina e Análise Critica da Jurisprudência. São Paulo: Saraiva, 2004.

BARROSO, L. R. O Direito Constitucional e a Efetividade de suas Normas: Limites e Possibilidades da Constituição Brasileira. 7. ed. atual. Rio de Janeiro: Renovar, 2002.

BONAVIDES. P. Curso de Direito Constitucional. 12. ed. São Paulo: Malheiros, 2002.

BUZAID, A. Da Ação Direta de Inconstitucionalidade no Direito Brasileiro. São Paulo: Saraiva, 1958.

CANOTILHO, J. J. G. Constituição Dirigente e Vinculação do Legislador: Contributo para a Compreensão das Normas Constitucionais Programáticas. Coimbra: Coimbra Ed., 1994.

CAPPELleTti, M. O Controle Judicial de Constitucionalidade das Leis no Direito Comparado. 2. ed. Tradução de Aroldo Plínio Gonçalves. Porto Alegre: Sergio Antonio Fabris, 1999.

CLÈVE, C. M. A Fiscalização Abstrata da Constitucionalidade no Direito Brasileiro. 2. ed. rev. atual. e ampl. São Paulo: Revista dos Tribunais, 2000.

CUNHA JUNIOR, D. da. Controle Judicial das Omissões do Poder Público: em Busca de uma Dogmática Constitucional Transformadora à Luz do Direito Fundamental à Efetivação da Constituição. São Paulo: Saraiva, 2004.

FERREIRA, S. A. Representação Interventiva e Iniciativa Exclusiva do Ministério Publico Estadual. Revista de Direito Administrativo, n. 164, abr.jun. 1986.

KRELL, A. J. Direitos Sociais e Controle Judicial no Brasil e na Alemanha: os (Des)caminhos de um Direito Constitucional ‘Comparado’. Porto Alegre: Sérgio Antonio Fabris, 2002.

LEWANDOWSKI, E. R. Pressupostos Materiais e Formais da Intervenção Federal no Brasil. São Paulo: Revista dos Tribunais, 1994. p.113.

LUÑO, A. E. P. Los Derechos Fundamentales. 6. ed. Madri: Tecnos, 1995.

${ }^{40}$ SANTOS, 2001, p. 213.

A \& C R. de Dir. Administrativo e Constitucional, Belo Horizonte, ano 6, n. 24, p. 87-96, abr.jun. 2006 
MENDES, G. F. O Controle Incidental de Normas no Direito Brasileiro. Revista Dos Tribunais: Cadernos De Direito Constitucional E Ciência Política, ano 06, n. 23, abr./jun. 1998a.

MENDES, G. F. Jurisdição Constitucional: o Controle Abstrato de Normas no Brasil e na Alemanha. 2. ed. São Paulo: Saraiva, 1998b.

MIRANDA, J. Manual de Direito Constitucional. Coimbra: Coimbra Ed., 1983. v. 4.

MIRANDA, P. Comentários à Constituição de 1967, com a Emenda n. 1 de 1969. 2. ed. São Paulo: Revista dos Tribunais, 1970.

MORO, S. F. Desenvolvimento e Efetivação Judicial das Normas Constitucionais. São Paulo: Max Limonad, 2001.

PIOVESAN, F. Direitos Humanos e Direito Constitucional Internacional. 5. ed. São Paulo: Max Limonad, 2002.

SANTOS, F. M. Intervenção Federal no Direito Brasileiro. 2001. Tese (Doutorado em Direito do Estado) - Setor de Ciências Jurídicas, Universidade Federal do Paraná, Curitiba, 2001.

SILVA, J. A. da. Curso de Direito Constitucional Positivo. 9. ed. São Paulo: Malheiros, 1993.

SOUZA NETO, C. P. Fundamentação e Normatividade dos Direitos Fundamentais: uma Reconstrução à luz do Princípio Democrático. Arquivos de direitos humanos, v. 4, 2002.

TAVARES, A. R. Tratado da Argüição de Preceito Fundamental: Lei n. 9868/99 e n. 9882/99. São Paulo: Saraiva, 2001.

TAVARES, A. R. Tribunal e Jurisdição Constitucional. São Paulo: Celso Bastos, 1998.

TEMER, M. Elementos de Direito Constitucional. 9. ed. São Paulo: Malheiros, 1992.

TORRES, R. L. O Mínimo Existencial e os Direitos Fundamentais. Revista de Direito Administrativo, n. 177, jul./set. 1989.

VELLOSO, C. M. Estado federal e Estados Federados na Constituição Brasileira de 1988: do Equilíbrio Federativo. Revista de Direito Administrativo, n. 187, jan./mar. 1992.

Informação bibliográfica deste texto, conforme a NBR 6023:2002 da Associação Brasileira de Normas Técnicas (ABNT):

KROL, Heloísa da Silva. Considerações sobre a ação direta interventiva e a proteção dos direitos fundamentais. A\&C Revista de Direito Administrativo e Constitucional, Belo Horizonte, ano 6, n. 24, p. 87-96, abr.jun. 2005. 